\title{
Retrieving Songs By Lyrics Query Using Information Retrieval
}

\author{
Padmaja Pulicherla, A. Prakash, J. Sasi Bhanu, C.V.P.R.Prasa, D.B.K.Kamesh
}

\begin{abstract}
Music is an all-time favorite interest of most of us and hence with this paper, a system is proposed to find songs based on a search of a song with a text from a lyric of the song including the title, artist, and album of a song. When we forget the title of the song and if we want to search a song from our playlist it becomes difficult to manually search for it, relying on existing system proves to be more time taking. The existing system includes the conventional method where we need to search manually on a search engine.

The proposed system describes a system that is an application which can help list songs easily and faster on searching based on the lyrics of the song. We have tried to achieve this by mapping multiple lyrics files with the audio versions. Another aspect is to retrieve songs of different language as many of us prefer to listen to music of more than one language. Getting information quickly and with best results is the key to achieve efficiency. By using this application, anyone can search for songs by creating their playlist by signing into the application.
\end{abstract}

\section{INTRODUCTION}

This paper describes a system which is designed to list songs based on a search for any phrase of the lyrics of the song or title of the song including artists and albums. It is a mode to simplify and provide ease over various present music applications. The current system proposed is a music application which helps a user to search various songs based on the input given in form of text or audio. The given input is considered as a query which is searched among the lyrics files using information retrieval technique like Algebraic methods using the Vector Space Model. The results of the lyrics files obtained are mapped to the audio files and the list of songs are displayed to the user. The results are displayed based on the term frequency. The output is displayed as a list of songs. The user can then select the required option from the set of given outputs. If there is only one song displayed, then it shows the song and starts playing it. Using an algebraic model to retrieve

\section{Motivation:}

- $\quad$ Through this paper, we aim to take the initial steps of searching a song with the phrases of the lyrics as the key.

-

Revised Manuscript Received on August 14, 2019.

Dr. Padmaja Pulicherla, Professor, Department of CSE, Teegala Krishna Reddy Engineering College, Hyderabad, Telangana, India.

Mr. A. Prakash, Associate Professor, Department of CSE CMRIT, Secunderabad, Telangana, India.

Dr. J. Sasi Bhanu, Professor, Department of CSE CMRIT, Secunderabad, Telangana, India.

DR. C.V.P.R.Prasad, Professor, Department of CSE, Malla Reddy Engineering College for Women, Secunderabad, Telangana, India.

Dr. D.B.K.Kamesh, Professor, Department of CSE, Malla Reddy Engineering College for Women, Secunderabad, Telangana, India.
- Many users listen to songs every day and when they want to listen to a song from their huge playlist. It becomes difficult to remember all the song titles. This application helps us to search songs based on words or phrases related to its lyrics.

This application helps users listen to their favorite list of songs.

\section{LITERATURE SURVEY}

The existing system includes the conventional method where we need to search manually on the internet. This is time-consuming as after getting the result, we might need to navigate to few URLs to find the song and play it. There are two interesting applications which help with lyrics or song search. Firstly, Shazam - It recognizes the song when it is played rather than recognizing a human voice. This might help us a few times while a song is being played, else it would help us when we sing a song that we remember. Secondly, Musixmatch - This app doesn't help us search according to lyrics rather it displays the lyrics when the song is played. This is helpful when we want to know the lyrics while the song is being played, but it has failed when we tried to search for a song using text from its lyrics as the key for this is to display lyrics while the song is being played.

\section{User Survey}

Our main target is users who love listening to music. This application gives users an easy and efficient platform for scanning and searching for songs of different genres and languages.

Our team approached different people in various fields and localities. We started a survey by sharing a form through social media and asking their opinions. The form included a few questions like:

1. How useful their music app is?

2. On an average how much time do $u$ spend on music on a weekly basis?

3. Can they search effectively?

4. Would you want the search the songs based on lyric file?

5. Would you try if it is for free? 
RETRIEVING SONGS BY LYRICS QUERY USING INFORMATION RETRIEVAL

\begin{tabular}{|l|l|l|l|}
\hline Respondent & Age & Role & Review \\
\hline $\begin{array}{l}\text { D.R. S. } \\
\text { Rajput }\end{array}$ & 40 & Manager & $\begin{array}{l}\text { It will be useful for } \\
\text { everyone }\end{array}$ \\
\hline R. Rahul & 23 & Student & $\begin{array}{l}\text { Interesting and need } \\
\text { not swap between } \\
\text { multiple apps }\end{array}$ \\
\hline $\begin{array}{l}\text { Samyuktha } \\
\text { B. }\end{array}$ & 16 & Student & $\begin{array}{l}\text { It will be helpful as it } \\
\text { reduces the time of } \\
\text { searching for songs }\end{array}$ \\
\hline K. Tanmay & 36 & Homemaker & $\begin{array}{l}\text { It's a good idea, but I'm } \\
\text { not sure if I really will } \\
\text { use it. }\end{array}$ \\
\hline
\end{tabular}

Table: User Survey to validate the idea.

Overall there is a positive review of the idea and the application based on their work and usage.

\section{System Overview}

The application helps the user to search for a song and play songs which the user has downloaded. When a user searches for a song then the lyrics are searched at the backend and the results are fetched. If there is a list of songs as the result, then the list of all possible song is displayed. If there is one song, then it starts playing after the search results are fetched. The system has nearly 100 songs during the time of initial development and testing of the basic features. These songs are fetched and stored on a remote server where there are lyrics file present already. The user mustdownload songs of their interest, like an online music application available with the offline feature to save songs to the device.

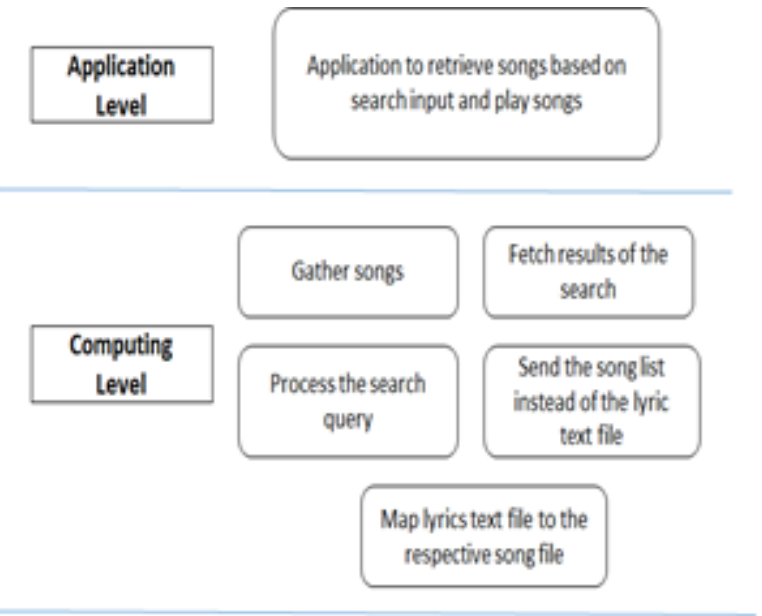

Fig. 1: Architecture of the entire system

\section{METHODOLOGY}

The major criteria for efficiency are that the results should be obtained quickly and efficiently as there are millions of songs present. To do obtain this we have used the Vector Space Model to obtain the results from a .txt file.

The algorithm used is described in Fig 2.

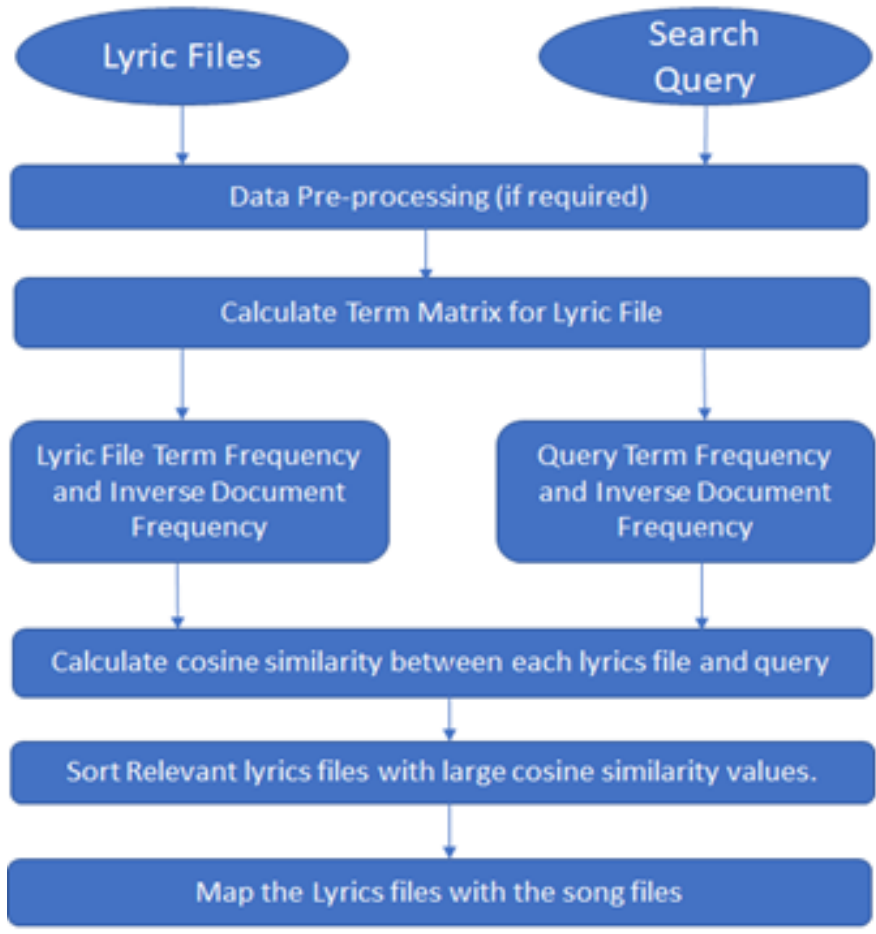

Fig. 2: Architecture of the entire system

The mathematical calculation is done by finding $\mathrm{k}$ terms in a document with the highest Term Frequency $(\mathrm{d}, \mathrm{t}) / \mathrm{n}(\mathrm{t})$ and use these terms to find the relevance of other documents.

Vector space model is defined in an n-dimensional space, where $\mathrm{n}$ is the number of words in the document set. Vector for document $\mathrm{d}$ goes from origin to a point whose ith coordinate is $\mathrm{TF}(\mathrm{d}, \mathrm{t}) / \mathrm{n}(\mathrm{t})$ The cosine of the angle between the vectors of two documents is used as a measure of their similarity.

Relevance Term Retrieving

- Term Frequency/Inverse Document frequency ranking:

- Let $\mathrm{n}(\mathrm{d})=$ number of terms in the document $\mathrm{d}$ $\mathrm{D}=\mathrm{d} 1, \mathrm{~d} 2, \mathrm{~d} 3 \ldots \ldots \mathrm{dn}$

- $\quad \mathrm{D}$ is the subset of documents $\mathrm{d}$, and each $\mathrm{d}$ having a subset of $\mathrm{w} d=\mathrm{w} 1, \mathrm{w} 2, \mathrm{w} 3 . \ldots \ldots \mathrm{wn}$

- $\mathrm{n}(\mathrm{d}, \mathrm{t})=$ number of occurrences of term $\mathrm{t}$ in document d. Relevance of a document $d$ to a term $t$ can be calculated by finding the term frequency in equation 1

$\mathrm{TF}(\mathrm{d}, \mathrm{t})=\log (1+\mathrm{n}(\mathrm{d}, \mathrm{t}) / \mathrm{n}(\mathrm{d}))$

The log factor is to avoid excessive weight to frequent terms Relevance of document to query $\mathrm{Q}$

$\mathrm{r}(\mathrm{d} ; \mathrm{Q})=\mathrm{TF}(\mathrm{d} ; \mathrm{t})=\mathrm{n}(\mathrm{t})$

that means $t$ " $Q$

Once the relevant files are obtained then the user can view them in the application and select which song to play as the flow described in Fig 3. 


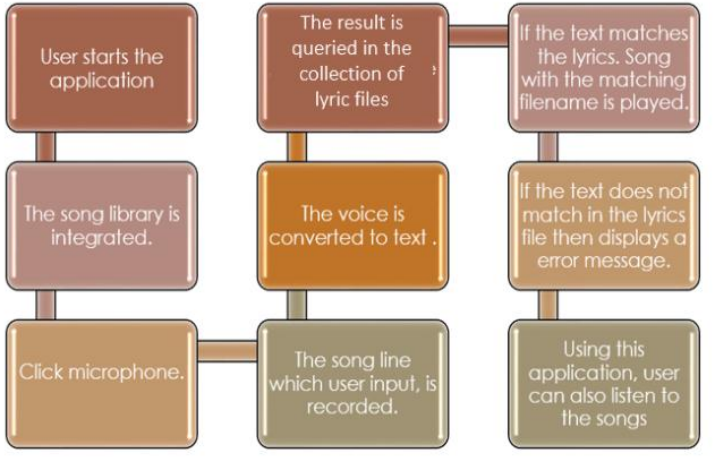

Fig 3: Flow of the events of the application

\section{RESULTS}

The songs have been obtained efficiently and played. The main aim was achieved successfully over a sample list of music files which have been added by us. Figure 4 shows the screen of the application where the user can give an audio query. And figure 5 is the resulting screen when the song is fetched and being played after fetching.

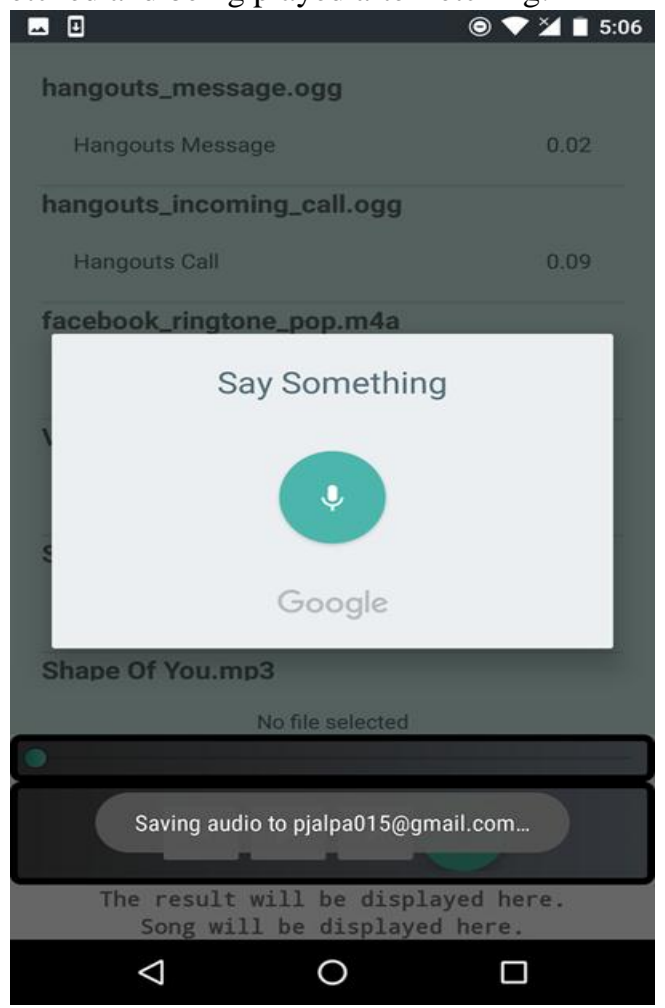

Fig 4: Screen to take the audio input of the query

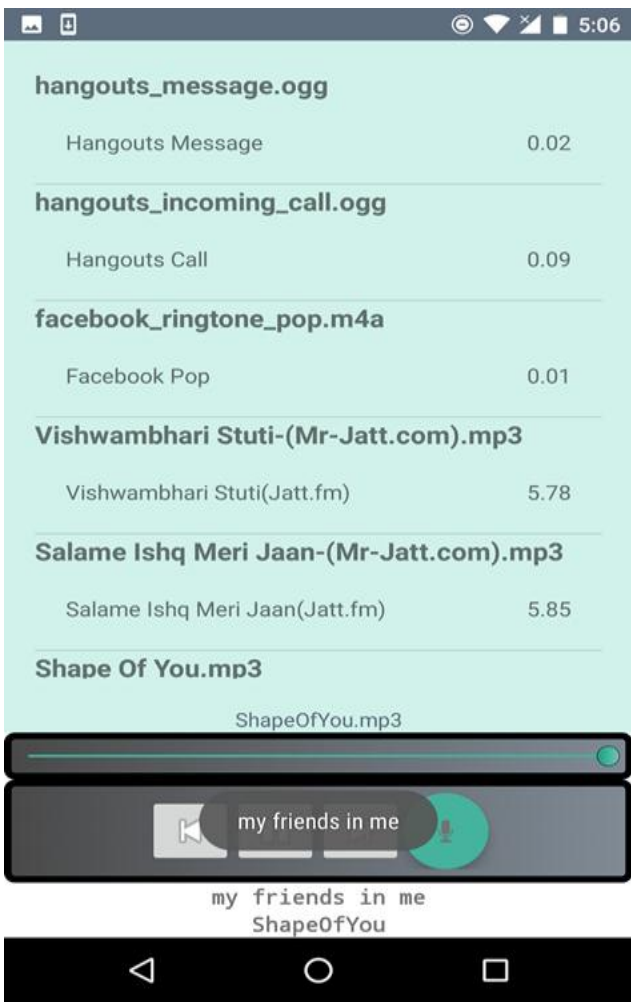

Fig 5: The resulting song has been obtained and is being played.

\section{CONCLUSION}

The aim of the project has been achieved with the help of retrieving the documents efficiently and playing the songs. In real time scenario to make the application more efficient, the audio files can be stored on a cloud and the search results should be obtained from them. This gives space for everyone to access most of the songs and the burden at device level can be reduced.

\section{REFERENCES}

1. Information Retrieval from database queries IEEE 2014

2. Ontology-based information retrieval for historical documents IEEE 2016

3. A Survey of Music Information Retrieval Systems Research Gate

4. Interdisciplinary Communities and Research Issues in Music Information Retrieval

\section{AUTHORS PROFILE}

Dr. Padmaja Pulicherla, Professor, Department of CSE, Teegala Krishna Reddy Engineering College, Hyderabad.

Mr. A. Prakash, Associate Professor, Department of CSE CMRIT, Secunderabad

Dr. J. Sasi Bhanu, Professor, Department of CSE CMRIT, Secunderabad

Dr. C.V.P.R.Prasad, Professor, Department of CSE, Malla Reddy Engineering College for Women, Secunderabad.

Dr. D.B.K.Kamesh, Professor, Department of CSE, Malla Reddy Engineering College for Women, Secunderabad.

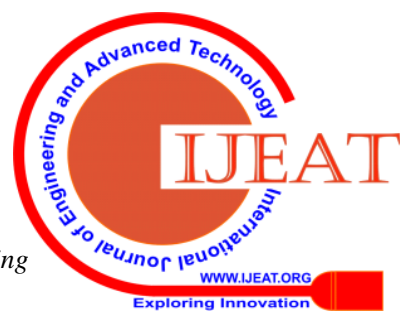

